ohan Dutta, Director of the Center for Culture-
Centred Approach to Research and Evaluation
(CARE) at Massey University talks with Sue Bradford, the centre's first activist-in-residence in Aotearoa New Zealand. The conversation outlines the role of community organising in communication for social change, with both Mohan and Sue drawing on their work in grassroots organising at the margins. Mohan and Sue detail the role of voice infrastructures at the margins as a basis for structural transformation. They critically interrogate the tensions that emerge in the relationships among communities, activists, and academics, and discuss how these tensions can be addressed in creative ways. The conversation wraps up with the authors' thoughts on the role of community organising in building socialist futures in the postpandemic world. 


\section{Community Organising: A Critical Dialogue}

\section{MOHAN DUTTA \& SUE BRADFORD}

SUE BRADFORD TO MOHAN DUTTA - What is the Center for Culture-Centred Approach to Research and Evaluation (CARE), and why have you brought your organisation to Aotearoa New Zealand?

MOHAN - CARE is an advocacy-based research centre in the School of Communication, Journalism, and Marketing at Massey University, drawing on the culture-centred approach in developing social-change solutions, and, in doing so, studying the processes of social change when they are controlled by subaltern communities. With an overarching emphasis on building voice infrastructures through collaborations with communities that are systematically and often violently erased, CARE develops interventions that seek structural transformation in solidarity with these communities. Over the last two decades, CARE has been collaborating with Indigenous communities, communities experiencing various aspects of poverty (hunger, inaccess to minimum wage, homelessness), low-wage migrant workers, sex workers, transgender communities, workers in the digital economy, survivors of genocide, and various movements and party organisations to develop communicative strategies that challenge structures of power. In Aotearoa New Zealand, CARE has been working on developing social-change interventions 
that address Māori health disparities, poverty, food insecurity, labour, and migration. In developing these social-change interventions, CARE often collaborates with community organisers and activists who teach us pedagogies of change.

Coming to live permanently in Aotearoa New Zealand emerged out of three years of reflecting on the next stages in the journey of CARE, as the situation in Singapore was becoming increasingly unsustainable. Collaborating with communities living in poverty, transgender sex workers, low-wage migrant workers in the construction industry, and domestic workers in the context of Singapore's authoritarian neoliberalism was becoming increasingly challenging. In my work, I describe Singapore's authoritarian neoliberalism as a form of extreme neoliberalism that pushes the mechanisms of the free market through the deployment of violence and other disciplinary techniques, simultaneously promoting itself as the Asian gateway for capital. For instance, low-wage migrant workers in hyperprecarious jobs are not allowed to organise and face the risk of deportation and/or imprisonment for speaking out against the state or for participating in protest. Activists and artists are harassed and imprisoned for publicly demonstrating without a permit or for protesting outside of the designated spaces for protests. The state uses what it calls 'out of bounds' (OB) markers to set limits on articulations of dissent. Described as 'Disneyland with the Death Penalty' by the journalist William Gibson, Singapore projects the image of a city state at the frontiers of smart urban futurism. This works through the erasure of the severe control exerted by the state on labour, collectivisation, and dissent. After having struggled through the challenges of state control, particularly in the articulation of labour and human rights, which emerged as key anchors to our work, it was time for CARE to move to a context where the principles of academic freedom, democracy, and justice were explicit commitments. Aotearoa New Zealand, with its acknowledgment of the role of the academic as the critic and conscience of society, felt like a good potential home for the work of CARE. The history of Māori struggles for indigenous rights, which offers a global template for the ongoing work of decolonisation, the active politics of equality, and the 
possibilities of theorising social justice from the Pacific, was an additional draw. With my partner finding a teaching position that worked for her, Massey felt like a great choice. My friend and colleague, professor Shiv Ganesh, who was then at Massey, had wonderful things to say about the organising climate in Aotearoa New Zealand. In the two years of being here, I have had the opportunity to learn from, and work with, activists such as yourself, to collaborate with communities experiencing poverty, and to build meaningful solidarities.

MOHAN TO SUE - Now, one of the concepts that you and I have often discussed is what the politics of building 'voice infrastructure' means in Aotearoa New Zealand. Drawing on your extensive work with grassroots movements, what would you say is the role of voice in imagining and sustaining a politics of equality?

SUE - Bringing into the public domain the voices of those who are living the day-to-day realities of unemployment, poverty, and housing inadequacy has been fundamental to the work of the grassroots organisations with whom I've primarily been involved. From 1983-1999, I was part of the Auckland Unemployed Workers' Rights Centre (AUWRC), as well as coordinating Te Roopu Rawakore o Aotearoa (the national unemployed workers and beneficiaries movement) for three years, from 1987-1990. I was also involved in helping to set up and run Auckland Action Against Poverty (AAAP), from 2010-2016. I came to this work after periods of unemployment and life as a sole parent on the domestic purposes benefit when I was young, and it has always been clear to me that the most effective voices in our movements have been those of people who have lived, or are currently living, through hard times themselves.

Some of the ways in which we endeavoured to strengthen and amplify our voices, and the voices of those with whom we worked, included:

- Becoming as effective as possible in media and public speaking work-and these days through social media as well—by tying 
sharp commentary on relevant issues of the time to the day-to-day realities of what we found in our work advocating with and for unemployed people and beneficiaries. There is no underestimating the importance of getting our literal voices out as far as possible, into as many spheres of public discourse as we can.

- Running participatory educational workshops so that people might better understand the economics and politics of the system in which we live. With knowledge comes both understanding and greater confidence in speaking out in different contexts. One of the greatest barriers low- and no-income people face in attempting effective input into political processes at any level is a lack of understanding of the structures of economy and society. This is why various forms of participatory educational processes are so important to us.

- Incorporating cultural work (creativity in the interests of the political kaupapa) into our activities in the 80s and 90s through singing and songwriting, poster and banner making, writing, street theatre, and other forms of drama. These activities both helped disseminate our views and realities more widely and also played a role in nurturing group solidarity.

- AUWRC published a monthly magazine, Mean Times, which was distributed widely to members, supporters, and the public. People were encouraged to contribute their own articles, poems, cartoons, and graphics. In more recent years, AAAP has been highly effective in using video clips, social media, and mainstream media as ways of amplifying people's stories and getting them out into the world.

- Right from the start, our groups organised demonstrations, pickets, and occupations at times when we felt these tactics were appropriate. We saw direct action as often the clearest way of magnifying voice, exposing and opposing those who blamed us, the victims, for the impacts of capitalism, and calling for alternative solutions to unemployment, poverty, and homelessness. 
Making way for the voices of those most affected is critical, but there are caveats to this. There is almost a worship of storytelling in some of the activist-training methodologies developed over the last couple of decades. There is indubitably power in narrative, but there is always the risk that it can be used as a rather pleasant substitute for action and/or for the hard work of building and sustaining organisations on the ground. Another danger is the temptation to focus on getting people's tragic personal stories into the public arena without giving enough thought to the consequences for them and their families. There have been all too many damaging instances of this over the years. In some situations, when handled carefully and well, this can be fine; but without care, people can suffer horrendous damage through public exposure. It is easy to fall into the trap of relying on narratives of individual hardship as the basis for the bulk of a group's media work, as journalists love these opportunities; but they can come at a heavy price. There are many subtleties to the use of voice. How we use it, who uses it, and when are all critical strands of imagining and building a transformed future.

SUE TO MOHAN - Can you give a couple of examples of projects you've worked on overseas, described in enough detail to show how the key elements of CARE's methodology operate in practice?

MOHAN - The neoliberal transformation of the globe, aggressively pursued since the late 1970s, is marked by a key discursive intervention: the construction of the poor as lazy and undeserving, leeches on the system. This narrative is often racialised, with larger representations of Indigenous communities, minority communities, and communities of colour among the poor. In this backdrop, the 'Singaporeans Left behind' advocacy campaign developed by community members living in poverty in the authoritarian context of neoliberal Singapore is a powerful example. In this collaborative work, an organically emerging advisory group of individuals and families living in poverty in Singapore guided the overarching research questions, the nature of our ethnographic work, research design, analysis of 
the findings, and development of the advocacy campaign, which sought to open up a conversation on poverty in Singapore.

Consider the backdrop of this project in 2012-2014, when it was initiated. The term 'poverty' itself is considered an $\mathrm{OB}$ marker, suggesting it is a term that could not be explicitly discussed in the state-controlled discursive sphere. Euphemisms such as 'low-income' are often used by the state and its establishment academics to parade the success of the development framework of the 'Singapore model'. The Singapore model is a model of city design that is sold by the state and global networks of elites (those at the World Bank, International Monetary Fund, and the World Economic Forum), presenting authoritarian techniques of disciplining populations and the deployment of state-sponsored violence as a form of technocratic management used to produce digitally enabled sustainable futures. As a knowledge economy, Singapore thrives on its marketing of the Singapore model to other nations in Asia, generating investment and revenue streams for Singapore-based planning, architecture, and development corporations. The Singapore model is marketed as a template for designing smart cities of the future, communicatively inverting state repression as efficient management through digital technologies. Against this backdrop, the advisory group of community members experiencing poverty sought to document their lived experiences and struggles with poverty, which they juxtaposed to the backdrop of Singapore's growth model and its seductions as a futuristic city. Based on the protocols generated by the advisory group, our research team conducted in-depth interviews with families living in poverty, recruiting residents from the rental blocks that are allocated for low-income households. By moving door-to-door and working simultaneously with our advisory group members, we were able to recruit more members into our advisory groups, who in turn supported the recruitment of additional members. The in-depth interview protocol further transformed as the interviews progressed. As the data started emerging, advisory-group members worked collaboratively with our research team in making sense of the data. Based on their sense-making through dialogue, the advisory group came up with the 'Singaporeans Left Behind' campaign. 
The campaign, as it was getting ready to be launched, faced several barriers, including directives from the state, mediated through the university management, for changes to be made to the campaign. The centre also came under the scrutiny of the state-university structure. Note here that universities in Singapore are extensions of the state, instrumentalising the directives that are issued by the state, although the state-university relationship is obfuscated through layers of opaque decision-making. I was sent an email from a university administrator asking why the centre runs social-change interventions and why it hosts conferences on social change (referring to a conference that was hosted earlier by CARE, hosting community organisers, activists, and academics). After I stated that this is the nature of CARE's academic work, referring to an earlier conversation I had with the administrator about the importance of academic freedom to the work of CARE, the university administrator demanded several changes be made to the campaign. The advisory group made decisions in collaboration with our research team on how to respond to the demands from the state-university structure. Whereas we were able to keep most of the advocacy interventions as planned, the title of the campaign was changed to 'No Singaporeans Left Behind'. The advisory group felt that this small change in the campaign theme left intact the key messages they sought to communicate. The campaign ran for a period of six months, produced a white paper based on the research findings, and was covered by the major state-controlled media in Singapore. One of the major media outlets ran a special issue on the campaign, with spaces for voices of many of the advisory-group members. The call, 'Join the conversation on poverty', became an anchor to transforming the discursive space in Singapore, generating several conversations and serving as a precursor to the current conversations on poverty, inequality, and neoliberal growth in Singapore.

The centre, however, now came under the state's radar, with questions raised regarding its purpose. 'Why is an academic centre doing social change work?' was a question that was repeatedly asked by the university management. In each of these instances, as director of the centre, I explained that its purpose was to study social change processes by practising 
these processes. This uneasy division between theory and practice became the subject of ongoing pressures from the state-university system. These challenges hit home the importance of activism within academia that disrupts the very division between theory and activism that is often artificially propped up to keep dominant structures intact.

Another example is from our work in rural West Bengal, in the Jangalmahal region, over the last two decades. A large part of Eastern India, including large sections of Jangalmahal, is home to Indigenous peoples. In the early work of the culture-centred approach, based on developing solidarities with Santalis, everyday structural oppressions were foregrounded as sites of transformation. Community voices started documenting hunger, the lack of access to healthcare, state-led development policies that expelled Indigenous communities from their livelihoods in forests, and police atrocities as the fundamental threats to health and wellbeing. This is the backdrop against which communities across Jangalmahal mobilised in protest, interrogating the state-corporate nexus and creating sovereign zones of local governance in resistance to the oppressive practices of the state. This uprising, referred to as the Jangalmahal uprising, was systematically co-opted by the Maoists and then repressed by the newly elected state government that came to power through collaboration with the Maoists and strategic manipulation of the protests.

The ongoing work of CARE seeks to co-create spaces for radical democracy at the grassroots, through people's participation and voice. Through door-to-door strategies, along with participant observations, community members are recruited. Open-ended, in-depth interviews that explore the meanings of health, well-being, and the good life offer conceptual anchors through which community members construct their narratives, depicting the structures that constitute their everyday lived experiences and struggles. These in-depth interviews serve as the basis for partnerships, as our team of academics and community researchers participate alongside communities to identify the challenges they face, the potential solutions to these challenges, and the strategies through which these solutions can be realised. Through our collaborations with 
communities in developing solutions, we collaboratively grasp the entry points for structural transformation. Voices of community members from the rural margins - recognised within the discursive spaces of policymaking and policy implementation - both shape and hold to account development policies and practices. Culture-centred interventions at the grassroots have taken the form of organising community-wide meetings, communitydriven petitions, meetings with development actors, and protests. These various forms of communicative interventions have resulted in communities articulating solutions to protecting Indigenous cultural practices and livelihoods, protecting trees in sacred spaces, building community-based health care, building roads, developing irrigation systems, and mobilising the state to create accessible sources of clean drinking water.

One lesson that emerges from this work is the incredible power of voices from the margins in disrupting structures of power and in co-creating transformative solutions that meet community needs. Also, when these voices speak up in ways that matter, structures of power attempt in several ways to silence these voices. One way to identify whether a culture-centred process is working is to test the response of the structures of power. When these structures - the state, the university, the board of trustees, or the private sector-are organising to silence or shut down your project, you can have some sense that it is working to disrupt their normative expectations.

MOHAN TO SUE - Given your many years of powerful activist work in Aotearoa New Zealand, can you think of instances when this tension emerges in your work, when the hegemonic structures of power are mobilised to shut down voices from the margins? And how, then, do you respond to these structures?

SUE - The deepest and most confronting tension in my activist work has been the one which lies at the heart of the struggle of unemployed workers and beneficiaries and their families for respect and survival. Right from the earliest days of forming AUWRC, at a time of high and rising unemployment in early 1983, our group (and others like it around the 
country) were fighting the notion that we, and those with whom we worked, were simply lazy dole-bludgers out to deprive taxpayers of their hard-earned money. Any income support was grudgingly given by the state. Politicians, media, and the public felt they had a license to abuse us in any way they saw fit. Even as unemployment rose drastically under the fourth Labour government's neoliberal reforms, unemployed people continued to receive the blame for their situation. One of our key slogans of that time was: 'Blame the system, not the victim'. We spent huge amounts of energy trying to get the message out there that it was both the capitalist system and governments' deliberate actions to create unemployment that were to blame, not the jobless and their families.

The political and cultural system in which we live has myriad ways of misrepresenting and vilifying the voices of beneficiaries through a mix of pity, charity, derision, blame, ridicule, and stereotyping. The people who worked in our groups, mostly as volunteers or very low-paid employmentscheme workers, were often characterised as stupid, dangerous, and dirty. Those whom we challenged were regularly surprised to discover that we could read and write, much less put a decent legal argument or policy proposal down on paper.

In the early days of representing unemployed people and beneficiaries at the government departments which so often refused even the most basic of entitlements, there were times when we were forced to use the tactics of direct street action to win our cases-for example, through pickets, occupations, and associated media work. As time went by, the departments began to realise that our advocates often knew the details of welfare policy and law far better than the government officials they were dealing with, and a hesitant respect started to grow for those carrying out frontline case work. This meant that in most situations we no longer needed to use the more militant tactics. Developing expertise in law and regulation that outstripped the departments' own was a key factor in achieving the ability to act more effectively.

During these years, another of the principal ways in which we responded to the vilification from public, media, and government was to build support 
on the ground. We pursued this actively not only with those with whom we worked every day but also through consciously identifying friends and allies in different sectors, from church and union people to academics and public servants, finding ways in which they could help to support our work, as we at times could support theirs. Within our groups, those of us who held core positions endeavoured to set examples that countered the stereotypes, by putting a premium on integrity in relationships. We deliberately cultivated a culture of solidarity and did everything we could to strengthen people's capacity to act effectively and to speak up politically. We encouraged ways of working that nurtured internal debate; used action-reflection methodology as a way of regularly analysing our work and learning from our mistakes; and ran our own skills and education workshops, as mentioned above. A huge amount of our counter-response was also through the use of effective media work and public speaking. We had a policy of accepting any speaking engagement, even if the context was alien or hostile. We knew that once we had an opportunity to tell our side of the story and put up our ideas for constructive solutions, we could frequently start to turn perceptions around. There was an ironic downside to all this, in that often enough an unemployed person would come and work with us for a while, gain skills and confidence, and then go off to a good job. This was, of course, a great outcome for the person concerned, but not so good for the group. It meant we were always starting the cycle again in a bid to keep our core infrastructure functional.

The most direct attacks on our organisations from government started after National was elected in 1990, immediately cutting welfare benefits and introducing legislation aimed at breaking the power of the unions. Effective efforts were made to withdraw funding from our groups even when agreements already existed. The most egregious attack occurred when police invaded the Auckland Peoples Centre after a three-day antiforeign investment protest in 1992, using a dodgy search warrant to baton charge us and arrest people as we sat inside our own building. A later court case found that what we termed an 'invasion' was not legally justified.

One of our responses to these types of offensives from the state was to 
continue to build and develop the Peoples Centres in Auckland, Manurewa, and Mangere, providing medical, dental, employment, beneficiary advocacy, hairdressing, chaplaincy, and other services to thousands of people. The \$10-per-month fee each family paid to belong to the Peoples Centres gave us some income that we had control over, which helped make up for the loss of funding support suffered after National came to power. A second aspect of our response was to maintain the political and educational side of our work through AUWRC, which itself played a key role in helping to sustain and develop the Peoples Centres. AUWRC went on to play a critical part in numerous street mobilisations and coalitions aimed at National's treatment of employed workers, unemployed workers, and beneficiaries, and its role in opening up Aotearoa New Zealand even further to foreign investment and control. We acted as a catalyst in bringing together groups to expose and oppose some of the hard truths behind the Asian Development Bank, CHOGM (Commonwealth Heads of Government), and APEC meetings of the mid-to-late 1990s. Third, we worked to build even stronger alliances with friends across sectors. Manifestations of this included the organising role AUWRC played with the national 'Building our own Future' project (BOOF), funded by the Conference of Churches of Aotearoa New Zealand in 1993-1994, resulting in the development of a Peoples Charter and in the establishment of other organisations including Kotare Research and Education for Social Change in Aotearoa, still in operation. Later on, we organised two national gatherings which crossed the academic-activist divide, with AUWRC and Massey University in Albany co-hosting conferences on poverty, unemployment, and welfare in which hundreds from the university and from the union and community sectors participated.

In a later generation of organising in this sphere, I was part of setting up AAAP from 2010 onwards. Based in Onehunga, AAAP advocates for unemployed people and beneficiaries with Work and Income, and works for a kaupapa of 'direct action, advocacy and education, mobilising against the neoliberal agenda on jobs, welfare and poverty'. As AUWRC did before it, AAAP had to start from scratch in earning credibility from 
the government department with which it interfaced, from the media and public, and in building a core of people able to sustain the group through years of minimal funding. Public denigration of beneficiaries continued, with comparatively recent examples including former prime minister Bill English comparing beneficiaries to crack addicts in 2014, and a 2019 comment by a Federated Farmers leader saying that the government will use tax reforms to pay for 'useless' beneficiaries. ${ }^{1}$ AAAP faced the task of building a reputation as well-informed and capable of credible debate and establishing a track record of exposing those in power very publicly. Effective media and social-media work, and a willingness to speak and debate publicly, went hand-in-hand with organising sharp, focussed street actions. As in the AUWRC days, AAAP has found it very difficult to raise funds, and survival is a constant struggle, dependent once again on friends and allies wherever they can be found.

In May 2018, the Labour-led government established the Welfare Expert Advisory Group (WEAG) to undertake a wide review of the welfare system. AAAP nominated a representative to the WEAG, but they were apparently not even considered for inclusion. At this kind of level, the exclusion of the loudest and most critical voices continues, while at grassroots AAAP's advocates and spokespeople maintain a voice in a space where there are few others. The hegemonic structures you talk about Mohan, continue to focus on marginalising and silencing the voices of unemployed people, beneficiaries, and their advocates. The responses go beyond what I have talked about here, but I hope this snapshot gives some sense of the way in which some of the groups with which I have been involved have attempted to overcome the huge disparities in power and agency in this vulnerable sector.

SUE TO MOHAN - What challenges has CARE experienced in this past year in Aotearoa New Zealand, and how have you worked with them?

1 Sandra Conchie, 'Bill English's cocaine reference slammed,' New Zealand Herald, 18 September 2014; Jennifer Eder, 'Federated Farmers Malborough president slams tax reform as funds for the "useless," Stuff, 25 March 2019. 
MOHAN - One of the key challenges for CARE, and for the culturecentred approach more broadly, is the ongoing tension between co-creating transformative spaces in solidarity with communities at the margins and negotiating the institutional logics as a centre located within the university. I am grateful for the tremendous support offered by the School of Communication, Journalism, and Marketing and the Massey Business School in sustaining the work of the centre. But the centre's location within the university also means that it is subjected to the pressures that contemporary universities negotiate in these neoliberal times-pressures from powerful board members, politicians, and business interests. After having dealt with the threats to academic freedom in Singapore (because our work on poverty and migrant health challenged state propaganda), I have to note that Massey University has been a space of great possibilities.

At the same time, CARE's programs like the activist-in-residence program actively seek structural transformation and therefore threaten ensconced power structures. When we had you there as our inaugural activist-in-residence in Aotearoa New Zealand, for example, there were pressures from powerful interests, especially given the disinvitation to Don Brash from Massey University around the same time. Right-wing blogs started targeting CARE; there were suggestions that CARE ought to invite Don Brash to debate with an activist of the Left. At these moments, it has been critical to point out the theoretical and empirical commitments of the centre to listening to the voices of the margins and basing the centre's decisions on these commitments. Similarly, when CARE invited Tame Iti as our activist-in-residence, I was made aware of donors who raised concerns, pointing to Tame's arrest record or labelling him a terrorist. Once again, at these moments, it has been important to point to the mission of CAREto co-create communicative infrastructures for the voices of the marginsand to anchor our articulations on these commitments. I suppose this is an ongoing challenge for any space in the university that seeks structural transformation, especially because of the increasing interplay of private and public interests that seek to keep power structures intact through control over processes of knowledge production. 
Part of the public work of CARE, and my own work, is lending solidarity to the critical voices that experience oppression when they speak out. This often translates into pressures from powerful forces who would like to silence these articulations of solidarity. For instance, earlier in 2019, some tweets in solidarity with the US politician Ilhan Omar were picked up by the Israel Institute of New Zealand. David Cumin, from the institute, got in touch with the vice chancellor and the pro-vice chancellor of Massey as part of a campaign that sought to portray me as an extremist, alongside other academics critical of Israeli policies. The institute put up a webpage labelling me and other academics critical of Israeli settler colonialism as extremists. Note here that Cumin, along with Brash, is a key member of the Free Speech Coalition that was born when Auckland mayor Phil Goff banned the far-right white supremacists Lauren Southern and Stefan Molyneux from council-owned venues. An anonymous whitesupremacist website has specifically targeted me for my work on whiteness. In the face of these threats, it is critical to the work of CARE to articulate its public mission: interrogating oppressive structures and seeking strategies for dismantling these structures. Although these responses can be both physically and emotionally laborious, it is vital to do this work of disrupting structures of power that silence. Similarly, CARE's activist interventions such as the 'decolonising anti-racist interventions' series are co-created with the goal of disrupting structures that systematically erase and silence.

In the ongoing work of CARE in Singapore, as I noted earlier, the centre came under scrutiny and was targeted for doing work that was contributing to social change by co-creating voice infrastructures at the margins. Questions such as 'why is CARE hosting a social change conference?' or 'why is CARE hiring human-rights activists as community researchers?' depict the powerful forces that seek to control the terrains of knowledge creation. As CARE has launched its advocacy campaigns designed by communities experiencing poverty in Aotearoa New Zealand, I am humbled to witness the ways in which they create registers for addressing structural challenges, anchored in the voices of households and communities experiencing poverty. In many ways, Sue, one might note 
that these challenges that arise when structures of power are disrupted and dismantled are the key sites of learning; they also offer evidence that our advocacy and activist interventions are working. How we respond to these challenges are vital pedagogic resources in the work of CARE.

SUE TO MOHAN - One of the biggest differences between the work of CARE and that of the groups in which I have been primarily involved is that CARE is university-based, bringing academic and funding resources to bear in supporting communities into action in countries overseas, and now here in Aotearoa New Zealand. One of the biggest challenges I see for your work here is that the funding situation for groups with any commitment to fundamental social and economic change is very difficult. Our community sector is highly restricted in its ability to politically advocate and still receive financial support, so I fear for the sustainability of projects once the university is no longer able to back them on the ground. Do you have ideas on how this challenge may be met?

MOHAN - As you noted earlier with the AAAP experience, finding funding as well as sustaining spaces where you can intervene is a challenge. Part of this is that funding is almost always located within power structures with particular political and economic interests. That is the materiality of funding. The NGO-ification of social change has meant that so much of the change itself has become an industry, with managers and auditors being paid large sums to serve corporate interests under the umbrella of social change. You look at, for instance, the frenzy around 'sustainable development goals' and the huge industries of professional management and impact measurement that have been built around them. For example, in the World Economic Forum, you have the 1 percent coming together to talk about addressing inequality. What does social change even mean when the discourse of inequality is co-opted by the global elite? In my opinion, the work of change that can happen in movements with a transformative agenda is in tension with the neoliberal co-option of social change. Against this backdrop, the challenge of securing funding to support the development 
of community-based, community-driven structural interventions is a difficult one, one that is continually negotiated in the neoliberal university. At CARE, we have to continually ask ourselves: how much funding do we need? What do we need to sustain ourselves? Which funding sources do we say 'no' to because of fundamental differences in ideology?

There are a few key points that emerge from the question of funding and material resources. First-and this, I think, is really important to acknowledge at the start-it seems that funding is almost always located within structures which have their own material interests. For instance, you see the NGO-ification of movements as noted earlier, with funding often taking the driver's seat, which then forces the radical and transformative spaces of peoples' movements into hegemonic structures, to be incorporated into corporate social responsibility programs and the mission of the World Bank. After all, the greatest funding source of participatory programs today is the World Bank. So funding is always political and set within power structures. The state and the university are also power structures in this sense.

Second, with the increasing neoliberalisation of tertiary education, university management is turning to private donors, who then hold sway over university decision-making through threats to pull funding. This is the environment CARE has to negotiate, especially with programs like the activist-in-residence, which threaten the neoliberal structure. As noted above, this was particularly the case when CARE invited you and Tame to share your wisdom, and you both offered amazing transformative anchors for social change. I am saying this to emphasise the political nature of funding and how that constitutes what we do at CARE and how we negotiate our environment. One way, then, that CARE negotiates this environment is by publishing journal articles, book chapters, and books in what are considered high-quality avenues, and which generate the sorts of metrics that universities immersed in audit cultures and rankings races are looking at. For instance, I shared with you the challenges to the work of CARE in Singapore, which paradoxically was in contradiction to the fact that CARE was publishing much of our work in high-impact journals, considered to be the point of seduction for the neoliberal university. 
Finally, coming back to the question of how you sustain work with community groups that are committed to structural changes, whether in the social, political, or economic spheres, it is important to identify what the fundamental capacities that you can build together are. While some of these capacities might need funding, others might not. There are areas where academics can contribute to community capacities through collaboration on research tools, documentation, and advocacy efforts. In that sense, I suppose what I am pointing towards is a long-term solidarity among academics, activists, and communities. This sustained partnership also becomes a way to transform universities; unless we can change the very sites where knowledge is being generated, we have little hope for intervening in the neoliberal structures in which we are living. Because so much of what we do at universities sustains the 1 percent, this fundamental restructuring of the university in the socialist imaginary is, I think, key. And a lot of that restructuring has to come from communities and activists, inverting the traditional power of expertise that academics have often held.

MOHAN TO SUE - As we wrap up this conversation, I wondered whether you could share some of your imaginaries for this kind of socialist transformation I am talking about, both in Aotearoa New Zealand and globally?

SUE - Conceptualising a different future than the one in which neoliberal capitalism currently entraps us is a key part of building that future; the two tasks are intertwined. If we cannot imagine a better world and the values that underpin it, we cannot build that world. And if we are trying to build something new, that starts now. There is no point waiting for utopia or some mystical point of revolution. And because the hard work of day-today organising, educating, and acting for change is intricately connected to the values and shape of what we're trying to build, there must be congruence between them. I suspect that one of the main reasons we fail so often on the radical Left is that we act as though that congruence doesn't matter.

We are living in extraordinary times. The ecological and economic crises spin faster and faster, deepened and magnified by the Covid-19 pandemic. 
The health and economic impacts fall disproportionately on the poorest peoples. In all-too-many places, the institutions and owners of the world's wealth continue to consolidate their power with right-wing populist parties and leaders increasingly at their beck and call.

One of the biggest questions on my mind at the moment is whether it is possible for us here in Aotearoa New Zealand to construct a kind of Left popular movement that does not mimic the populism we associate with the Right, and which can learn the hard lessons from some of the attempts made by our sisters and brothers in struggles overseas, which have so often come unstuck, like Momentum in the UK and Syriza in Greece. I keep coming back to this question, because unless we find ways of articulating a vision for a different kind of future that moves beyond capitalism and is backed by congruent and effective organisational forms, we on the Left will continue to endure endless factionalising and defeat. Conscientisation and mobilisation will only be effective if we can appeal to ordinary people with language and culture that they can genuinely understand and support.

If we continue to prove incapable of this kind of organising, the cycle of Labour- and National-led governments enmeshed within capitalism will persist unbroken; unions will remain weakened by difficulties in moving beyond the demands of day-to-day organising; community-based and tangata whenua organisations will all too often continue to be colonised and divided by competitive funding models or lacking in resources altogether if they dare to raise their heads above the political parapet; those parts of the academy that do endeavour to speak up and act are at risk of enforced compromise or closure because of the corporate-managerialist mandate which currently suffuses the sector.

There is not room here to fully canvass possible imaginaries for socialist transformation', only to dabble with a few thoughts I have at the time of writing. I am also grounding this with particular reference to what we have already been discussing in this dialogue: the work of CARE (here and overseas) and my experience, particularly in working with unemployed people and beneficiaries in Aotearoa New Zealand.

First, 'socialist' is itself a fraught term, so for convenience I'll use 
the definition I created for 'Left' as part of my $\mathrm{PhD}$ research: 'Left: A commitment to working for a world based on values of fairness, inclusion, participatory democracy, solidarity and equality, and to transforming Aotearoa into a society grounded in economic, social, environmental and Tiriti justice'. ${ }^{2}$ A key strand of a 'socialist imaginary' that I think worth exploring at present includes how we might more effectively bring together the theoretical world of the academy and the practical experience of grassroots activists and public intellectuals in ways that genuinely support organisational and educational work on the ground. Where academics and activists work together, the challenges we face include differences in how we use language, in how we enact relationships, in accountability and power, and in the valuing or otherwise of activist labour. One of the constant tensions in this relationship is the casually dangerous assumption that the ideas and knowledge of those who are in highly paid jobs in the academy are somehow worth more than the experience, values, and understanding of the low paid and unpaid with whom they may work on common projects. I do not in any way accuse CARE of this assumption; one of the most interesting aspects of your methodology is your genuinely respectful approach to the people with whom you work, and the placing of them at the centre of your projects.

CARE has brought new ideas and methods to our comparatively isolated country, just as others have done in the past. For example, the groups with whom I worked in the 80s and 90s learned much from activists who came from places like Latin America and the Philippines. The impact of globalisation in the decades since means that New Zealanders are now even more in touch with ideas and practitioners from the rest of the world. One of the advantages of these increased migration flows and exchanges is that our practice can continue to be sharpened, as long as we keep our eyes and minds open to the possibilities offered by those with experience in forms of community and union organising other than those to which we are accustomed.

2 Sue Bradford, A Major Left-Wing Think Tank in Aotearoa - An Impossible Dream or Call to Action? (PhD diss., Auckland University of Technology, 2014), 18. 
For those of us who are tangata Tiriti (tauiwi, including Pākehā), there is much work to be done on how we can strengthen our capacity as a collective, or series of collectives, to enter into relationship with tangata whenua in meaningful ways. This should include a constant reflection on how Tiriti-grounded relationships can be built in to the day-to-day implementation of our goals and striving to make this happen in practice; learning the true history of this country; and creating opportunities where education and forward-thinking analysis can help move us into a space where we on the tauiwi Left can more genuinely respond to challenges laid down, for example, by the Matike Mai report. ${ }^{3}$

Facing up to the urgency of the climate crisis is the key issue of our times, aligned as it is with the economic-inequality crisis, and propelled into even harsher reality this year by the impacts of the pandemic. The struggles for economic, ecological, and Tiriti justice are intrinsically linked. This means that whatever area-sectorally or geographically-that we happen to be focusing on, it is critical that we work together towards both strategies and solutions that take into account the urgency and scale of the climate crisis in a way that doesn't simply turn it into another source of profit for the hyper-wealthy elites.

Whatever area we may be engaged with at a given moment, our exploration is deepened if we take into account the scale and urgency of the climate and economic crises and the implications of a grounded Tiriti framework as one within which we look for alternatives and solutions. Over the last year, I've been part of discussions on everything from the dairy industry, tourism, urban planning, and degrowth through to welfare, employment, transport, and housing (and much more), where the adoption of this framework has led those involved to far more penetrating collective analysis than we would have achieved in similar discussions in the past. In this work, we take a commitment to climate justice as a starting point, alongside an understanding that it is not enough just to talk. We must also act, in every way we reasonably can.

3 Matike Mai, 'He Whakaaro Here Whakaumu Mō Aotearoa: The Report of Matike Mai Aotearoa - The Independent Working Group on Constitutional Transformation,' Auckland, Matike Mai, 2016. 
This leads directly back to the question of how we organise, in this time and place, and where the points are at which we might begin to strengthen our ability to build a new world within the shell of the old, while also continuing our work to expose and oppose the worst features of neoliberal capitalism. As mentioned already, our weaknesses are many, and when I look around, I continue to see huge gaps in organisation on our side of the political spectrum. At the community level, these include a shortage of unemployed workers, beneficiaries, and peoples' housing organisations able to carry out direct political action and upfront advocacy and community-based economic development. There is also the absence of a coherent climate-justice movement (or movements) capable of uniting employed workers as well as unemployed workers and others outside the paid workforce. All this is going to become even more important as unemployment rises with the economic impacts of Covid-19. The school climate strikes are brilliant, as are the many other actions NGOs and others are taking on climate issues - but without a movement (or movements) that unites people across sectors and location, we will always be on the back foot. At the parliamentary and broader political level, at time of writing there is still no political party or parties which carry what I would identify a clear 'Left' agenda as defined here, and which is also capable of mobilising ordinary people on a mass basis.

So, having painted such a negative picture of where we're at with organising, it's only fair that I offer a few thoughts about how we might begin to fill some of the gaps. At a community level, the old-fashioned notion of 'community economic development' - as opposed to social enterprise or social entrepreneurship - is a key strand of the path forward in taking local action for climate justice. Strengthening and extending different forms of community, cooperative, tangata whenua, and collective initiatives as preferred ways of creating and maintaining decent jobs and getting socially and ecologically useful work done is one such path forward.

The BOOF project of 1993-1994, mentioned above, was a vibrant coming together of groups and movements across sectors and from all parts of the country. One strand of its work was the holding of a series of 'Peoples 
Assemblies' around Aotearoa New Zealand, culminating in a national Peoples Assembly at which a 'Peoples Charter' was agreed—a brief but encompassing document that included a statement of common belief, a vision for the future (local and international), and a series of commitments to action. I sometimes wonder whether there is something to be learned from what we did back then-not an attempt to repeat activity which was suited to a very different time, but to examine whether a process relevant to this moment could be used to create a charter or manifesto for our times as part of a deliberate conscientising and mobilising process. Such activities can be useful organising tools in themselves, and, if done well, the outputs that are created can be sources of communal vision and hope. We need that, to take on the power of capital.

The question of the 'party' is one of never-ending debate, and of continuous trial and error. On the back of my experiences as an active participant in both the Green and Mana parties, and in several extraparliamentary organisations in the past, I think one aspect of the way forward may be the creation of two parties on the Tiriti-grounded Left, one which is Māori-led and Māori-focussed (as with Mana), and one which is tauiwi-focussed, although anyone may be welcome to join either. Such parties could have a sister-sister relationship, without having to operate as one. The possibility of two such complementary parties grounded in pursuing the promise of te Tiriti on a Left and tino rangatiratanga kaupapa feels to me like one of the most acute lessons from the experience of the Mana project.

When thinking about economic, social, Tiriti, and climate justice, we also need to be aware that the structures of patriarchy have not magically disappeared. Women and non-binary people continue to suffer violence, oppression, frustration, and impotence in many ways. Children suffer too, as voiceless and powerless objects. I am interested in what a party might look like if women and non-binary people were at its core, and where the interests of children and young people were given as much weight as those of adults. I have never been part of a party where standing up to, and countering, the patriarchy was put at the centre alongside issues of class, 
climate, and racism/Indigenous struggle. I would be very interested in seeing where this might go if we had a crack at it.

SUE TO MOHAN - So, Mohan, these are just a few of my 'imaginaries for socialist transformation' that you've been asking about. As I was writing this last response, we had fully entered the era of Covid-19. I wonder if you would like to make a final contribution to this dialogue focussed on any thoughts you might have about the pandemic and its impacts on community organising, at least as far as we can judge our context in mid-2020?

MOHAN - Sue, thanks for sharing these powerful registers as anchors to our journey ahead here in Aotearoa New Zealand, although I also sense there are vital lessons here for how we craft futures for the Left across the globe. Coming to the pandemic we are in the midst of, many of the communicative inversions circulated by neoliberal ideology have been made visible - the lies that sustain the neoliberal common-sense are right in front of us. We have much work ahead of us as academics and activists to keep making visible these lies, the pathologies of neoliberalism, and the 'market will save us' fundamentalism. How we keep our attention on these inversions and dismantle them for good is what I see as the real challenge in this window of opportunity.

Also, I see this issue of co-creating infrastructures for the voices of the margins as urgent and necessary work. We should be asking these questions: who are the margins amidst the pandemic? How are these margins being created and reproduced? Whose voices are being erased and who is being invisibilised as the neoliberal structures respond to Covid-19? These are vital questions at this moment. For instance, in our work with hyper-precarious migrant workers in India, Singapore, and Aotearoa New Zealand, we find that the rendering of these workers as invisible is integral to the perpetuation of violence through the structures of the state and private capital. The very issue of who we consider deserving of labour rights and welfare resources and who we consider undeserving forms the infrastructure of the neoliberal ideology, continuing to disenfranchise and 
discard migrant workers who are already at the margins.

Mechanisms put in place by the state such as citizenship and migration work paradoxically legitimise these forms of disenfranchisement, and there is little actual collective organising and labour activism to secure some of the basic rights for migrant workers. When the pathways of claims-making are tied to citizenship, migration-related policies work well to reproduce and circulate this 'use and throw away' culture. I see this as one of the most vital challenges amidst Covid-19 and post-Covid-19: urgently building unions, networks of solidarity, and legal frameworks that both secure the collective-bargaining rights for migrant workers and state resources that are accountable to migrant workers. New kinds of imaginations of internationalism and worker rights are also necessary. That workplaces need vital registers for organising is another clear lesson. How we dismantle the pernicious effects of over four decades of neoliberal reforms and take back the radical capacities of unions is a vital question. The health-andsafety challenges experienced by essential workers foreground the vitality of re-imagining what is essential in our economies and working from that imagination to strengthen the fight for decent wages, decent working conditions, and decent protections.

On a similar note, we need to carefully consider the impact of Covid-19 on the poorest in our communities. The ideology of the 'deserving beneficiary' has been resurrected in how support is being organised by the New Zealand government and needs to be actively challenged. Attention should be paid to the needs of those households and communities at the very margins of our societies. Here, I appreciate your discussion of community economic development. So what is community economic development going to look like when led by the 'margins of the margins' of communities, anchoring the very idea of development in the voices of those who have been historically erased? I see the pandemic as an opening for transforming how we carry out public programs and welfare delivery, an opportunity to radically transform them by building decision-making infrastructures that those at the margins of communities can participate in. This, to me, is the actual work of radical democracy that lies ahead of us. Demands for universal 
basic income, universal housing, universal food, and universal healthcare can emerge from these community spaces of voice democracy.

As to Māori rights in Aotearoa New Zealand, the pandemic makes visible the racist, colonial structures we inhabit, with the ongoing erasure of Māori voices and Māori imaginaries. The iwi-led checkpoints demonstrate the positive and life-sustaining role of Māori organising. Simultaneously, the racist attacks on the checkpoints are indicative of the whiteness that forms the basis of the racist socio-cultural organisation of this country. I agree with your call for those of us who are migrants, and Pākehā, to place our bodies in solidarity with Māori struggles for sovereignty. In the midst of the pandemic, we are also witnessing a new wave of Black Lives Matter protests, which render visible the racist societies we inhabit. This racism has been fed by the white supremacy that is normalised in politics. Consider the possibilities of solidarities when Indigenous struggles are connected with the struggles against the pernicious effects of slavery and migrant struggles. The racist inequalities we witness in the US have similarities with everyday features of social organisation in Aotearoa New Zealand, although the contexts of these struggles differ substantially. How we dismantle these racist ideologies through local, regional, and international solidarities is another vital challenge of our times.

Finally, the pandemic has witnessed the resurgence of the rhetoric of kindness, which forms a key element of the Covid-19 policy architecture in Aotearoa New Zealand. Kindness as a trope plays a powerful role in erasing critical interrogation. Yet now is the time to critique and interrogate power and attend to the structural inequalities in our societies that have been illuminated by the pandemic. Altruism can also be seductive as a capitalist trope that keeps the existing power configurations intact. Going forward, perhaps we ought to centre care, social justice, and radical democracy as the anchors to re-organising our communities, Aotearoa New Zealand, and the global order.

These are some initial thoughts. Thank you, Sue, for suggesting this question as a way for us to wrap up this dialogue. I am hoping that across Aotearoa New Zealand we can have many such conversations that push us toward actively creating other worlds. 